\title{
Environmental planning and management in traditional market: a study at lbuh Market (Payakumbuh) and Pandansari Market (Balikpapan)
}

\author{
$S$ Sunarto $^{I^{*}}$, Sessario B Mangkara, and Miftahul Arozaq ${ }^{2}$ \\ ${ }^{1}$ The Department of Environmental Sciences, Sebelas Maret University, Surakarta, Indonesia \\ ${ }^{2}$ Urban Resilience Initiative and Collaboration (URIC), Surakarta, Indonesia
}

\begin{abstract}
Traditional market is a piece of urban movement which have mixed activities. At present, the management of the traditional market Indonesia is still not well implemented and a trader's community also give impact to environmental pollution. The research objective is to analyse a solid waste generation and green open space around the traditional markets and construct map of environmental planning and management. This research was conducted at Ibuh Market (Payakumbuh) and Pandansari Market (Balikpapan). The method used in this study is to integrate environmental information resources from thematic maps, Geographic Information Systems (GIS), observation, and interviews to the management of traditional market. The results of this study indicate that Ibuh and Pandansari markets have a good environmental management especially on the reduction of waste generation because an optimal the operational of compost house and waste bank. In terms of environmental planning, the manager of Pandansari Market does not have the commitment to provide green open space and the UHI forming factors will increase where the market is surrounded by mixed buildings. At the same time, Ibuh Market has sufficient green open space and can reduce the UHI phenomenon. Furthermore, in the future the management develop a model of environmental management based less waste and eco-tourism development.
\end{abstract}

\section{Introduction}

Traditional market is a piece of urban movement which have mixed activities. Traditional markets function as a transit space in the changeover of goods and services in an area and develop evoking diversified activeness in urban areas [1]. The function of traditional markets in an urban areas is very fundamental for the urban society and also in the suburban area with the purpose to carry out their daily necessities [2].

*Corresponding author: rm.sunarto@staff.uns.ac.id 
However, traditional markets with dense movement of urban society have many challenges to protect and improve the quality of environmental condition. At present, Indonesia as a country that has a traditional market is still attached as a public space that is dirty, sloppy, minimal facilities, and uncomfortable [3]. The management of traditional markets is still minimal causes the provision of physical facilities and not to play an optimal role. This is one of cause to Urban Heat Island (UHI) in traditional markets due to dense activities that are not well managed. Also, the management of traditional market do not have an environmental planning and management document. Therefore, this problem leads to excessive use of electricity, waste management not optimal, and selection of vegetation in green open spaces which not suitable.

Balikpapan City and Payakumbuh City are some examples of the cities in Indonesia which have high economic activity, and also have the risk of environmental pollution. Environmental planning and management that are not well managed and reduced a resilience of the environment, mainly around traditional markets. The researcher focused on the impact of solid waste management and green open space to explain the evaluation of environmental planning and management in traditional markets and their impact on UHI.

Taking from all the situation above, Government of Indonesia (GoI) has several options to improve in terms of environmental quality of traditional market. One of the main solutions is the professional management in traditional markets could be upgraded for better environmental condition. In addition, environmental planning and management and social engineering also become a primary part for the market manager. In concern of resolving the problems and challenges in traditional markets, this study assessed the situation through an environmental planning and management by using Geographic Information Systems (GIS) and remote sensing analysis.

Visual spatial analytics tools such as GIS clearly produce the assignment of identifying and selecting the priority areas of research location [4]. These visual spatial analytics deliver existing and extensive information to solid waste management and green open space decision making and pinpoint opportunities for a coordinated effort to guide urban transformation in a manner that will take benefit of all the ecological and social functions offered by public space for example traditional market and urban forest [5,6]. In addition, GIS are an appropriate tool for addressing complex spatial query by serving GIS users to analyse and existing data or support decision-making [7].

This study uses GIS tools to find out the capacity of green open space areas and related factors that influence UHI around traditional markets. Whereas waste generation in traditional markets is used to find out how much waste is managed by market managers and its impact to UHI. So that the research objective is analyse a solid waste generation and green open space around the traditional markets and construct map of environmental planning and management in traditional market.

Green open space or vegetation in public space is useful for the benefits on the local microclimate. Vegetation can be an indicator of Surface Temperature Dynamics (STD) in urban areas. The more vegetation cover, the STD will be cooler [8]. On the other hand, the occurrence of UHI in urban areas is caused by the less of green open spaces, vegetation, rivers, streams, and other non-urban spaces [9].

Environmental planning and management are one of the important things in maintaining the existence and contribution to deliver the needs of the community and maintaining the quality of the environment. The choice of location, accessibility, design and management of open spaces such as traditional markets that improve the quality of people's lives can be the main thing in creating sustainability in the traditional markets [10].

This study proposes the evaluation concept of environmental planning and management in urban areas, especially in traditional markets. Good environmental planning and management can explain the strategy of market management in dealing with UHI phenomena 
and the impact of pollution caused by traders' activities. Moreover, this study explains the development of urban environmental management strategies in two different cities [11].

\section{Material and methods}

This research uses GIS methods to develop a description related to environmental planning and management in traditional markets. Before develop GIS and remote sensing analysis, we create thematic maps to integrate environmental information resources, observation, and interviews to the management of traditional markets. Data collected from two markets in two different city category (Big City (Balikpapan) and Medium City (Payakumbuh)) in September-December 2018. Administratively, this research is placed in Balikpapan (Pandansari Market) and Payakumbuh (Ibuh Market) which are presented in Figures 1. Primary data is obtained through observation and interview.

The variables of (a) impact of solid waste management and (b) green open space are needed to explain the evaluation of environmental planning and management in traditional markets and their impact on UHI. This step was carried out using thematic maps and remote sensing (Landsat 8 satellite imagery).

In meeting the analysis of solid waste management in each market, researchers conducted an analysis of solid waste generation based on the results of previous studies [12] and SNI S 04-1993-03 [13]. Researchers analysed secondary data in each market, namely how much solid waste is generated by the entire traditional market community every month. The researcher made a range of the weight scale of solid waste according to the city classification, i.e. Ibuh Market is 0,100 (medium city) and Pandansari Market is 0,200 (big city). This analysis is to find out one of the forming factors of UHI. The reason for choosing garbage as UHI factors is because it is a human activity which is the biggest source of pollutant emissions around traditional markets. In addition, to producing pollutants from the solid waste generation, human activities also produce heat which has an effect on increasing the temperature, namely anthropogenic heat [12], such as distribution of merchandise that uses transportation, domestic energy use, and dense activities.

To obtain the evaluation of environmental planning and management implementation in these two traditional markets, researchers conducted interviews with market managers. Some questions that were asked to market managers included: (1) the master plan of market management that was environmentally friendly, (2) supervised the case of environmental pollution and (3) decisive action on the perpetrators of environmental pollution or not in accordance with applicable regulations in traditional markets.

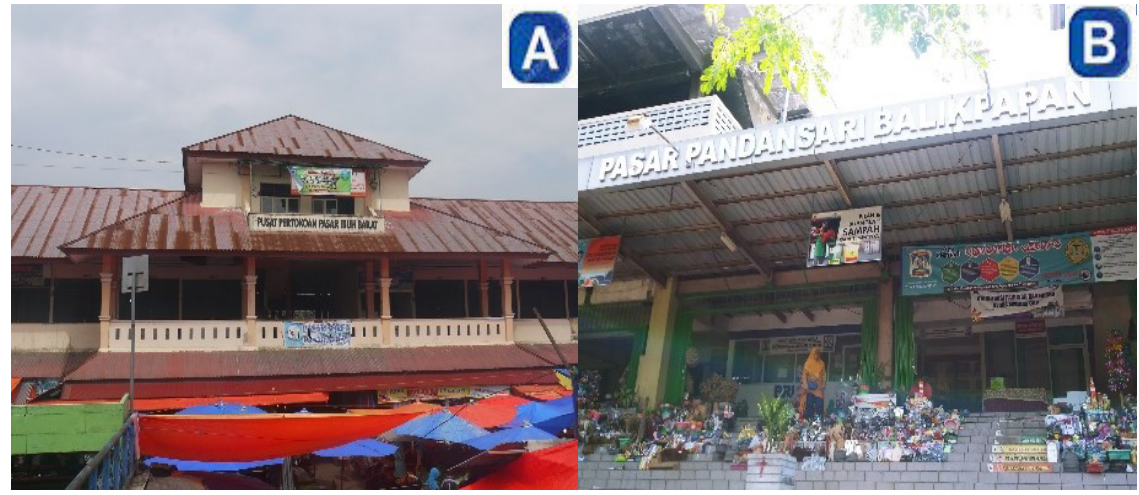

Fig. 1. (A) Ibuh Market, Payakumbuh City and (B) Pandansari Market, Balikpapan City 


\section{Results and discussion}

Based on observation and an interview with market managers, Ibuh Market and Pandansari Market show good management of compost houses and waste banks and contribute to the reduction of solid waste generation in each market. Ibuh Market has a market area of 45,000 $\mathrm{m}^{2}$ and after multiplied by the amount of solid waste weight of 0,100 to 135 tons/month. While data in the field states that solid waste generation in the Ibuh Market is estimated at 117 tons/month, there is a difference of 18 tons because solid waste has been managed in compost houses and waste banks. This is similarly found at Pandansari Market where the market area is $15,710 \mathrm{~m}^{2}$ and after multiplied by the weight of solid waste amounting to 0,200 to 94,26 tons/month. Data in the field states that solid waste generation at Pandansari Market is estimated at 86 tons/month, so there is a difference of 8,26 tons which Pandansari Market can reduce solid waste generation from composting activities and waste banks. The detailed estimation data of solid waste generation and the amount of solid waste in three different traditional market is shown in Table 1.

Table 1. Estimation of solid waste generation and the amount of solid waste in two different traditional market

\begin{tabular}{|c|c|c|c|}
\hline & $\begin{array}{c}\text { Ibuh Market } \\
\text { (Medium City) }\end{array}$ & $\begin{array}{c}\text { Pandansari Market } \\
\text { (Big City) }\end{array}$ & Source of Data \\
\hline Area of Market $\left(\mathrm{m}^{2}\right)$ & $45.000 \mathrm{~m}^{2}$ & $15.710 \mathrm{~m}^{2}$ & Secondary Data \\
\hline $\begin{array}{c}\text { Amount of solid waste } \\
\text { (ton/month) }\end{array}$ & 117 ton/month & 86 ton/month & Secondary Data \\
\hline $\begin{array}{c}\text { Estimation of solid waste } \\
\text { generation (ton/month) }\end{array}$ & 135 ton/month & 94.26 ton/month & Secondary Data \\
\hline
\end{tabular}

\subsection{GIS and Remote Sensing Analysis}

After observing and obtaining thematic maps, researchers made maps in each market to get an overview of environmental planning and management in traditional markets. In general, the map made explains the traditional market area, mixed building area, residential area, and green open space area. Based on remote sensing imagery, Ibuh Market has more adequate green open space compared to Pandansari Market. This situation makes the condition of Pandansari Market less comfortable and the UHI phenomenon is more felt because Pandansari Market is located on the coast.

Ibuh Market is the largest traditional market in Payakumbuh, located on Ahmad Yani Street No.114, Daya Bangun, West Payakumbuh, Payakumbuh City with coordinates $0^{\circ}$ $13^{\prime} 49.0$ "S $100^{\circ} 38^{\prime} 09.0^{\prime \prime}$ (Fig. 2). The West Ibuh area ( $\pm 2 \mathrm{Ha}$ ) was built in 1982 which was funded by the Presidential Instruction No. 7 of 1982/1983, while the East Ibuh area $( \pm 2.5$ Ha) was built in 1983 which was funded by the Presidential Instruction No. 10 of 1983/1984 [14].

In terms of environmental planning, Ibuh Market has medium level green open space which located on the west and east sides of West Ibuh and East Ibuh respectively. In addition, there is also a green open space area provided in front of West Ibuh and surrounding the settlements. This research supports the previous studies in which the greater the percentage of vegetation coverage will reduce the formation of UHI [15].

Ibuh Market located is in the middle of the city and can be reached by the public. However, based on interviews with market managers, Ibuh Market has not managed a waste water treatment systen and this resulted in direct pollution to Batang Agam River. 
In regards with solid waste management, Ibuh Market can reduce waste generation which around 18 tons because solid waste has been recycled to compost houses and waste banks. This shows that environmental management (especially regarding waste problems) is well managed and resulted into UHI reduction at Ibuh Market.

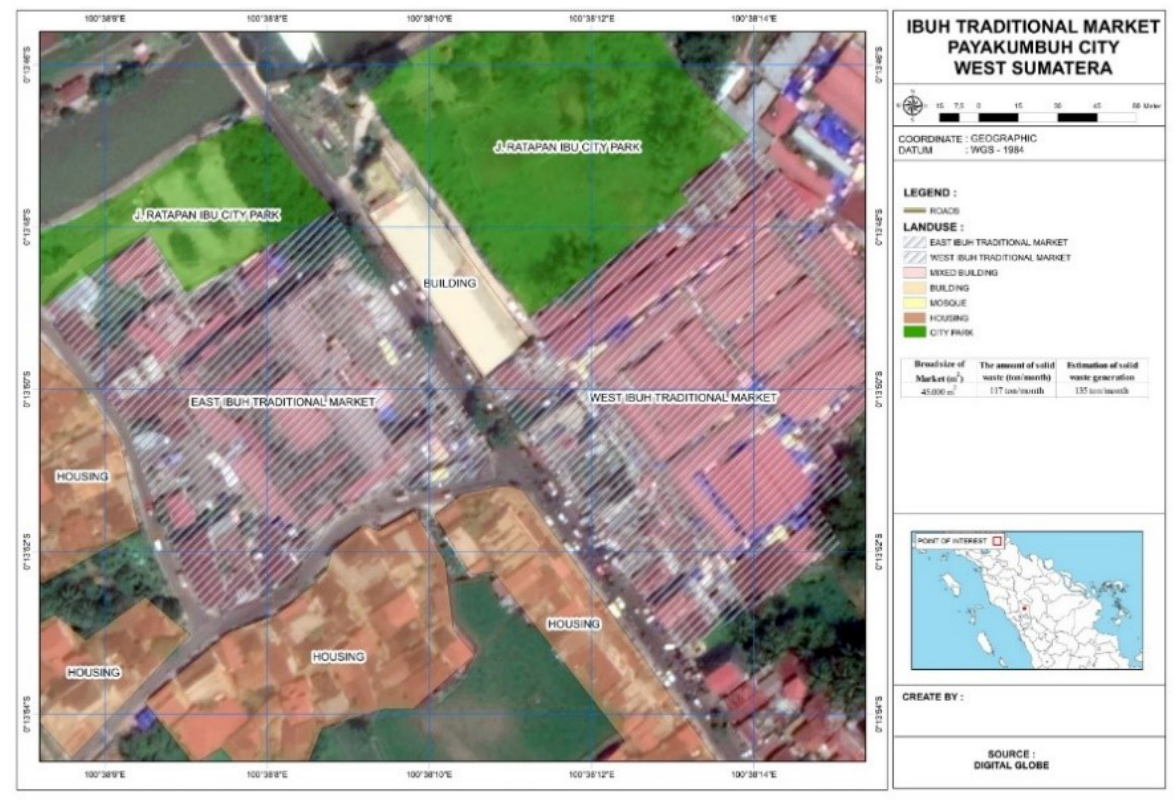

Fig. 2. Map of Environmental Planning and Management at Ibuh Market, Payakumbuh City

Pandansari Market is a wholesale market in Balikpapan City located on Jalan Pandan Wangi RT. 026 Margasari, West Balikpapan, Balikpapan City with coordinate point $01^{\circ}$ 14'14.8 "S 116 49'30.3" E and located at an altitude of \pm 25 meters above sea level (Fig. 2) [16]. Pandansari Market is located close to the sea and functions as a pier and loading and unloading of fish catches. This is closely related to economic infrastructure (fish trading activities) and the environment (coastal environment). Pandansari Market is surrounded by shops, offices, and housing.

Pandansari Market was established in 1960. Over time, the condition of the market infrastructure has improved where initially a wooden building was turned into a permanent building in 1996. On the other hand, Pandansari Market does not have an environmental planning document so around the market created by mixed buildings that contribute to the making of UHI. While the area of green open space at Pandansari Market circle the market area but it is still small size. In addition, market managers explained that Pandansari Market has no plans to increase green open space. In conclusion, environmental planning at Pandansari Market does not work effectively and tends to increase the phenomenon of UHI.

The location of Pandansari Market is strategic because as fish trading activities and can be reached by the public. However, based on interviews with market managers, Pandansari Market has not managed waste water and this directly pollutes Balikpapan coastal environment.

Concerning to solid waste management, Pandansari Market also can decrease waste generation which reduced around 8,26 tons because solid waste has been handled in waste bank and compost houses. This indicate that environmental management, particularly waste problems, can be managed well and resulting into UHI reduction at Pandansari Market. 


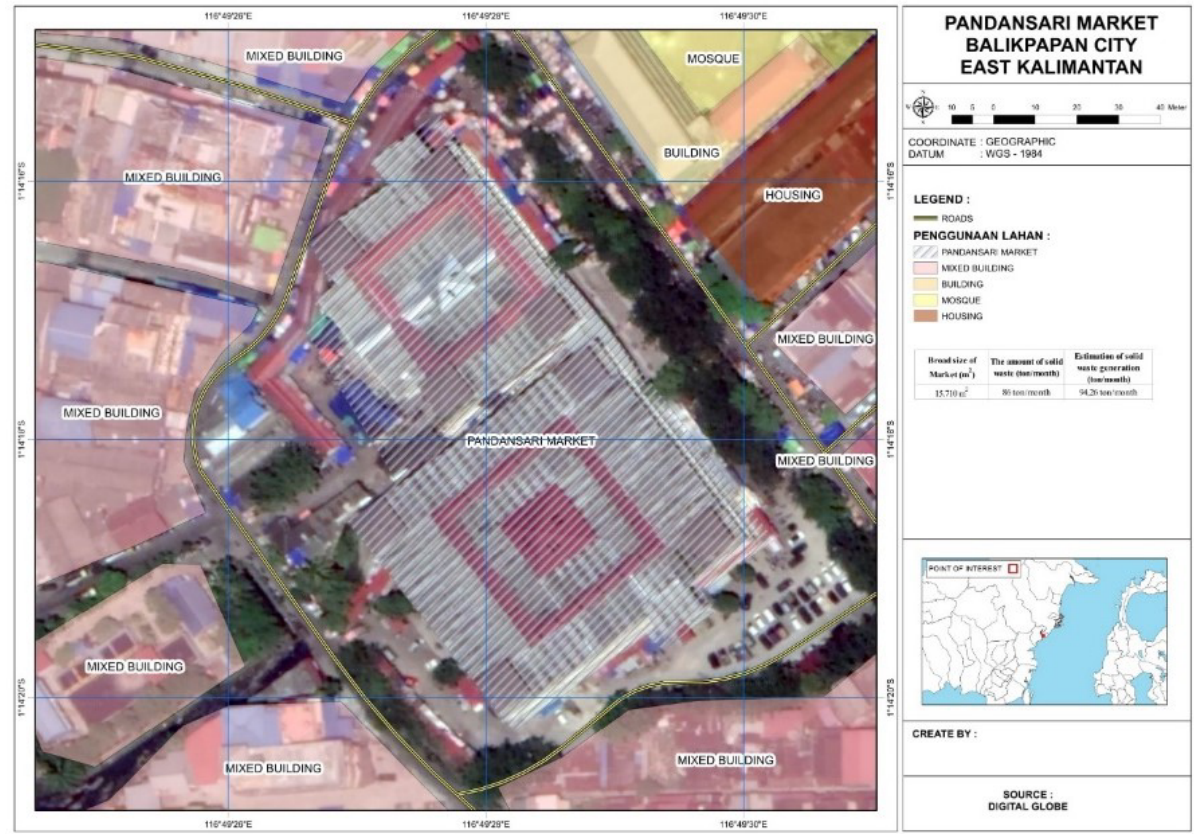

Fig. 3. Map of Environmental Planning and Management at Pandansari Market, Balikpapan City

This article gives an impression of GIS techniques and remote sensing used for managing the environmental problems of solid waste disposal and green open space management. However, the presentation of data in this research can still be developed for further research, such as the presentation of Land Surface Temperature (LST) and Normalized Difference Vegetation Index (NDVI) map data in each traditional market with a different time or period. This research is a preliminary study to evaluate environmental management in traditional markets.

\section{Conclusion}

This study concludes that Ibuh and Pandansari markets have a good environmental management particularly on the reduction of waste generation because an optimal the operational of compost house and waste bank. In terms of environmental planning, the manager of Pandansari Market does not have the commitment to provide green open space and the UHI forming factors will increase where the market is surrounded by mixed buildings. At the same time, Ibuh Market has sufficient green open space and can reduce the UHI phenomenon. The present work has shown that the reduction of solid waste generation and green open space areas can be used to minimize the phenomenon of UHI.

GIS and remote sensing tools play a big role in environmental planning and management in traditional market and have limitless application. GIS and remote sensing provide a platform for effective data input, retrieval, update, visualization, analysis, modelling among other functions. This research is expected to be applied to public spaces in an urban area that has dense activities and has environmental risks. Furthermore, in the future the management of traditional market develop a model of environmental management based less waste and eco-tourism development. This is related to the problem of waste that can be started from traditional markets and increased economic activity by making traditional markets as environmentally friendly tourist sites. The researchers propose this solution because the 
function of traditional markets not only as a selling buying spot but also a socio-culture interaction and life conception for urban people [17].

The researchers expresses recognition to Urban Resilience Initiative and Collaboration (URIC) Indonesia team who have facilitated in developing a GIS and remote sensing analysis. Additionally, researchers thank all of the parties who have contributed upon this research.

\section{Reference}

1. T.S. Sirait, Identification of traditional market characteristics that cause traffic congestion in Semarang City (Graduate Thesis of Dept. of Urban and Regional Planning, Diponegoro University, 2016)

2. Herminza, The relationship of knowledge and attitudes of traders with the practice of waste management at the Rangge Senta Market in Ketapang (Media Article, 2018)

3. Ministry of Trade Republic of Indonesia. Report Document: Community Market Development (2015)

4. J.M. Sanchez-Lozano, J.A. Bernal-Conesa, LUP 63, 86-97 (2017)

5. M.C. Dwyer, R.W. Miller, A 25, 102-107 (1999)

6. M. Singh, D. Evans, B.S. Tan, C.S. Nin, PO 10, 4 (2015)

7. B. Yatsalo, V. Didenko, A. Tkachuk, ISSC 1, 11-30 (2010)

8. R.H. Jatmiko, The use of thermal infrared channel imagery for the study of changes in land coverage and temperature as indicators of urban climate change in Yogyakarta (Thesis of Postgraduate Program, Gadjah Mada University, 2015)

9. L. Tursilowati, SD 3, 43-64 (2005)

10. O.P. Agboola, M.P. Azizul, M.H. Rasidi, I. Said, RS 62, 87-106 (2018)

11. J. Leitmann, Sustaining cities: environmental planning and management in urban design (McGraw-Hill, 1999)

12. E. Damanhuri, T. Padmi, N. Azhar, L.T. Meilany, LPM ITB (1989)

12. Indonesia National Standards, Retrieved from: https://core.ac.uk/download/pdf/11716534.pdf

13. Danamon Peduli. Rapid appraisal pasar sejahtera program report (Media Article, 2018)

14. S. Wicahyani, S.B. Sasongko, M. Izzati, G 11, 196-205 (2014)

15. Central Statistics Agency of Balikpapan City, City of Balikpapan in 2018 (2018)

16. R. Pamardhi, Planning for traditional Javanese markets in Yogyakarta Region (Undergraduated Thesis of University of Sydney, 1997) 